\title{
Evaluation of Variability of Watershed Hydrological Partitioning: The Case of Mormora River, South Eastern Ethiopia
}

\author{
Girma Kebebew Tufa, Ebbawak Saboka Megarsa \\ Faculty of Hydraulic and Water Resources Engineering, Arba Minch Water Technology Institute, Arba Minch, Ethiopia
}

\section{Email address:}

girmakebebew92@gmail.com(G. K. Tufa),Ebbasaboka@gmail.com (E. S. Megarsa)

\section{To cite this article:}

Girma Kebebew Tufa, Ebbawak Saboka Megarsa. Evaluation of Variability of Watershed Hydrological Partitioning: The Case of Mormora River, South Eastern Ethiopia. Journal of Water Resources and Ocean Science. Vol. 10, No. 5, 2021, pp. 132-138.

doi: $10.11648 /$ j.wros. 20211005.15

Received: September 1, 2021; Accepted: September 28, 2021; Published: October 12, 2021

\begin{abstract}
Water resources management in a watershed requires the quantification of the water potential. This is usually achieved by the estimation of the hydrological and meteorological characteristics of the watershed using observed data to carry out statistical estimates. Hydrological and meteorological data for the Mormora watershed were collected to analyze the hydrologic partitioning behavior of the watershed. The available data include a daily record of stream flow data from 1990 to 2007, a thirty years (1983-2012) monthly average precipitation at meteorological stations with in or near the watershed, and a 31 years (1981-2011) maximum and minimum temperature data at the same meteorological stations. The missed data of stream flow was in filled by simple regression method, and an outlier test, F-test, and T-test was computed for the data to check its quality. Necessary information about the geography of the area was obtained from LuLc, Soil, River, DEM, and climate map of Ethiopia, using ArcGIS software. Daily stream flow was converted to monthly scale and was partitioned to base flow and direct runoff using WHAT software. The maximum and minimum temperature data were used to estimate the potential evapotranspiration of the watershed using the 1985 Hargreaves equation. Average areal rainfall was estimated by Thiessen polygon method using ArcGIS software. Following these, the annual water balance of the watershed was analyzed using water balance theory. The inter-annual variability of the water balance, and hydrologic indices were analyzed. The relationship between climate and landscape is also studied. The result shows that the Horton Index and Humidity Index of the watershed are relatively constant with a coefficient of variation, $\mathrm{Cv} \leq 0.127$. Finallyconclusionsaredrawn,andthedifficultiesin making hydrological and meteorological estimates in a watershed with little or no data are highlighted.
\end{abstract}

Keywords: Mormora River, Watershed, WHAT

\section{Introduction}

\subsection{Background}

The movement of water through the continuum of the soil, vegetation, and atmosphere is an important process. Understanding the water balance in relation to climate and catchment characteristics provides insight into the complex processes operating over a range of spatial and temporal scales [13].

It is also essential for hydrologists to improve the understanding of the controls on the growth and water use of terrestrial ecosystems in order to predict the effects of climate change and improve management of watersheds for flood control, water supply, biodiversity, and environmental watershed services [15].

Land surface hydrology involves the study of the exchanges of water and energy between the land and the atmosphere and the movement of water within and over the land surface [6]. How space-time variability in precipitation interacts with spatial heterogeneity of soils, topography, and vegetation and is partitioned into spatiotemporal variability of runoff, evaporation, and soil moisture storage are fundamental questions that underpin hydrologic predictions of all kinds. This hydrologic partitioning is usually expressed in terms of a dynamic water balance, which can be 
manifested in various characteristic signatures of catchment responses representing variability at a range of time (and also space) scales [11].

Current methods for prediction of eco hydrological systems response to a changing climate is based on historical observations and assumptions of system stationary, which does not provide a reliable guide for future acclimation of vegetation or changes in watershed structure [8].

Evidence suggests that Ethiopia has not yet achieved the full potential of its surface and groundwater resources [1]. In developing countries like Ethiopia water is a crucial resource. However watershed studies have not been done systematically [4].

\subsection{Description of the Study Area}

Mormora watershed is found in Oromia regional state, in Borena zone; combining Uraga and Odo Shakiso weredas. The outlet point of the catchment is located with $38: 48: 0 \mathrm{E}$ and 5:41:0 $\mathrm{N}$ absolute location in Genale river basin. The catchment has a total drainage area of $1316 \mathrm{~km}^{2}$. The elevation of the area ranges from $1600 \mathrm{~m}$ a.m.s.l. to $3000 \mathrm{~m}$ a.m.s.1 [10].

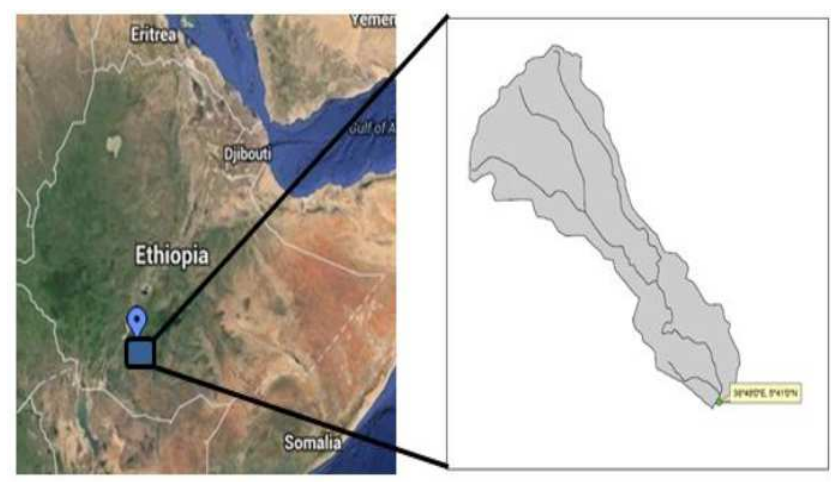

Figure 1. Location of Mormora Watershed.

Mormora watershed has Weyna-Dega and Dega climate. About $76.82 \%$ out of the total area exhibit W. Dega (equivalent to sub temperate) climate and $23.18 \%$ of the total area has Dega (equivalent to temperate) climate. A watershed is said to be hyper arid if $\mathrm{HuI} \leq 0.05$, Arid if $0.05 \leq \mathrm{HuI} \leq 0.2$,semi-arid if $0.2 \leq \mathrm{HuI} \leq 0.5$, dry sub-humid if $0.5 \leq \mathrm{HuI} \leq 0.65$, humid if $\mathrm{HuI} \geq 0.65$. According to this classification Mormora watershed with average humidity index of 0.74 is a humid watershed.

Most of the area of Mormora watershed is characterized by a disturbed high forest land cover. Even if their area extent is small; bushed scrubbed grassland, dense mixed high forest, moderately cultivated area and open grassland are also available [14].

General observations from Google Earth also indicate the area has a good land cover.

Table 1. Land use land cover summary.

\begin{tabular}{lll}
\hline Land cover & Area & \% Out of total \\
\hline Open Grassland & 81.339 & 6.18 \\
Disturbed high forest & 1174.592 & 89.247 \\
Moderately cultivated & 40.536 & 3.08 \\
Dense Mixed High Forest & 19.609 & 1.490 \\
Bushed Shrubed Grassland & 0.039 & 0.003 \\
Total & 1316.115 & 100.00 \\
\hline
\end{tabular}

\section{Materials and Methods}

\subsection{Data Collection and Data Characteristics}

A daily based stream flow record of eighteen years at only one station i.e., at the outlet, monthly maximum and minimum temperature record of 31 years, and monthly rainfall record of 30 years at 56 stations, uniformly gridded over the watershed are available for Mormora watershed.

As stated above the stream flow data is recorded at one station, that is the outlet, but the temperature and rainfall data are, data records from satellite and meteorological station data points in a combined way. Spatial resolution is $10 \mathrm{~km}$ and temporal resolutions are Monthly. In this project, we used monthly gridded climatic data with $10 \mathrm{~km}$ spatial resolution. The following table shows the summary of datasets used in this study.

Table 2. Input data description.

\begin{tabular}{|c|c|c|c|c|c|}
\hline Data & station & Temporal scale & Spatial scale & Period of record & Remark \\
\hline Stream flow & Watershed outlet & Daily & - & 1990-2007 & With missing \\
\hline Max To & Gridded (satellite + Met. Station $\}$ & monthly & $10 \mathrm{~km} * 10 \mathrm{~km}$ & $1983-2012$ & Full data \\
\hline Rainfall & Gridded (satellite + Met. Station $\}$ & monthly & $10 \mathrm{~km} * 10 \mathrm{~km}$ & $1981-2011$ & Full data \\
\hline
\end{tabular}

\subsection{Software Used in the Study}

In this study a Microsoft spreadsheet has been used extensively. Mathematical calculation and data organization of the study was done by Microsoft spreadsheet software. Activities related to the geography of the watershed like, delineating the catchment area, drawing different maps of the watershed, and extracting different information like; soil distribution, climatic condition of the area, topography etc..., has been done by Arc GIS version 10, software with its extensions like HEC GEOHMS.

A Web Based Hydrograph Analysis Tool (WHAT), is also used in this study. This software is especially used to separate direct runoff and base flow out of the total stream flow recorded. The software is online, in which the stream flow data prepared in appropriate format (i.e. table delimited or space delimited) is uploaded online and filtering technique is selected based on the reason available [9]. 
Table 3. Data sets and software used summary.

\begin{tabular}{lll}
\hline Data & Process & Software used \\
\hline Stream flow data & Base flow separation & WHAT \\
Max \& Min To & PET estimation & spreadsheet \\
Monthly precipitation at each satellite station & Arial rainfall estimation by Thiessen polygon & Arc GIS 10.4 \\
DEM, Arc Info & Extraction by geographic information of area & Arc GIS 10.4 \\
DEM & Catchment centroid control & HecGeoHMS \\
\hline
\end{tabular}

\subsection{Hydrograph Separation}

In many catchments, base flow is an important component of stream flow and, therefore, base flow separations have been widely studied and have a long history in the science of hydrology [2]. In general, there are two type of base flow separation techniques based on the nature of the hydrology [3].

\subsubsection{Event-Based Base Flow Separation}

Some base flow separation methods are better suited to analyzing hydrographs for individual rainfall-runoff events. A few simple examples are; constant straight line method, straight line with slope, and variable slope method [5].

\subsubsection{Continuous Base Flow Separation}

Double Parameter Digital Filter Technique/ Recursive Filtering Method is selected. At each time step:

$$
B k+1=\left\{(1-B F I \max ) * \alpha * B F I \max * \mathrm{Q}_{\mathrm{k}+1\}} /\left(1-\alpha * \mathrm{BFI}_{\max }\right)\right.
$$

$$
\mathrm{R}_{\mathrm{k}+1}=\mathrm{Q}_{\mathrm{k}+1}-\mathrm{B}_{\mathrm{k}+1}
$$

BFImax maximum value of long term ratio of base flow to total stream flow 0.80 , for perennial streams with porous aquifers, 0.50 , for ephemeral streams with porous aquifers, 0.25 , for perennial streams with hard rock aquifers and $\alpha$ is base flow filter parameter.

Base flow filter parameter (the recession constant a, which can be derived from statistical analysis of the recession curves of the hydrograph by default: $\alpha=0.98$ ).

The stream flow hydrograph of Mormora River has been separated to direct runoff and base flow using recursive filtering method. This method is more efficient, since it have additional parameter which can limit the quantity of base flow not exceed 0.8 times total stream flow [12].

\subsection{Base Flow Estimation}

Using double parameter recursive filtering method, the base flow separation of Mormora river stream flow is computed, using WHAT online software [7].

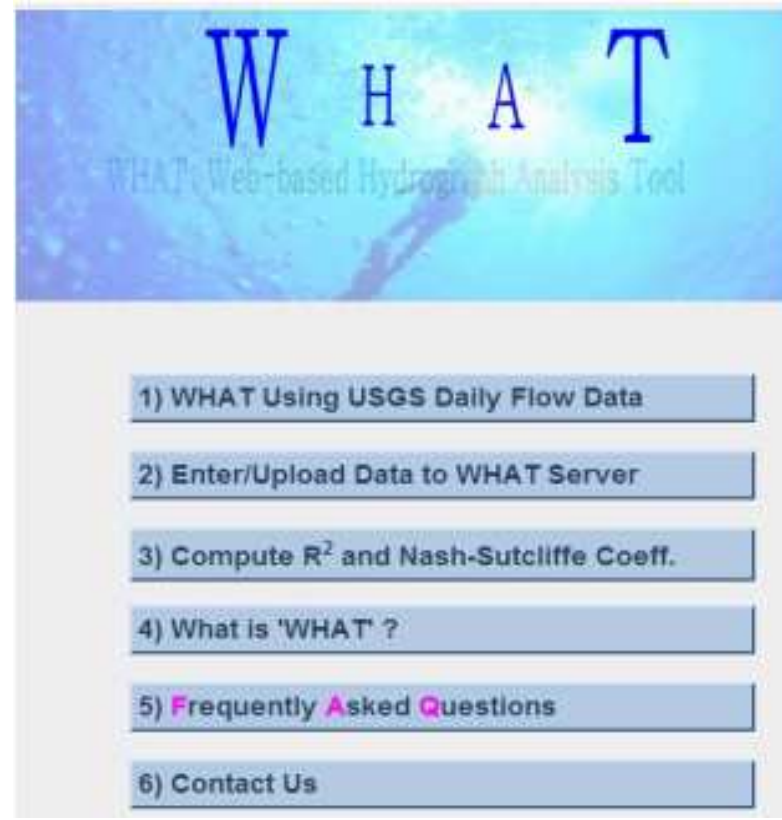

\section{File Upload Successful !!}

\section{You uploaded 0 file [ ] totalling total bytes.}

Figure 2. WHAT online software interface.

\section{Results and Discussions}

The annual water balance component for years from 1990 to 2007 is presented below. As it was stated earlier in the methodology section, $\mathrm{P}$ is total annual precipitation, $\mathrm{Q}$ is total annual stream flow, $\mathrm{S}$ is direct runoff, $\mathrm{U}$ is the base flow, $\mathrm{W}$ is soil available water which is called wetting, and $\mathrm{V}$ is vaporization. 
Table 4. Annual water balance components from 1990 to 2007.

\begin{tabular}{|c|c|c|c|c|c|c|}
\hline \multirow{2}{*}{ Year } & \multicolumn{6}{|c|}{ Elements of Annual Water Balance: Unit in (mm) } \\
\hline & $\mathbf{P}$ & $\mathbf{Q}$ & $\mathbf{S}$ & $\mathbf{U}$ & W & $\mathbf{V}$ \\
\hline 1990 & 1142.24 & 286.60 & 166.74 & 119.85 & 899.10 & 779.25 \\
\hline 1991 & 947.06 & 159.66 & 93.08 & 66.59 & 836.99 & 770.41 \\
\hline 1992 & 1306.67 & 293.30 & 147.46 & 145.83 & 1139.52 & 993.70 \\
\hline 1993 & 1147.46 & 478.88 & 338.01 & 140.85 & 791.20 & 650.35 \\
\hline 1994 & 1048.34 & 288.46 & 189.21 & 99.24 & 847.27 & 748.04 \\
\hline 1995 & 1328.27 & 382.94 & 269.65 & 113.28 & 853.79 & 740.51 \\
\hline 1996 & 1328.11 & 425.29 & 277.46 & 147.81 & 997.01 & 849.20 \\
\hline 1997 & 1299.20 & 275.33 & 203.54 & 71.78 & 1045.17 & 973.38 \\
\hline 1998 & 1182.19 & 419.14 & 259.45 & 159.68 & 910.26 & 750.58 \\
\hline 1999 & 1006.74 & 419.14 & 252.63 & 166.49 & 731.81 & 565.32 \\
\hline 2000 & 1120.28 & 444.69 & 314.78 & 129.90 & 755.92 & 626.02 \\
\hline 2001 & 1217.49 & $486 . .3$ & 262.91 & 223.11 & 935.18 & 712.08 \\
\hline 2002 & 1047.28 & 328.89 & 174.35 & 154.54 & 837.67 & 683.13 \\
\hline 2003 & 975.52 & 364.64 & 192.31 & 172.32 & 787.36 & 615.04 \\
\hline 2004 & 1005.90 & 527.81 & 249.11 & 278.69 & 776.30 & 497.61 \\
\hline 2005 & 1128.53 & 643.79 & 331.24 & 312.53 & 809.10 & 496.54 \\
\hline 2006 & 1194.22 & 484.14 & 220.93 & 263.20 & 947.95 & 684.75 \\
\hline 2007 & 1342.36 & 784.93 & 380.22 & 404.68 & 911.81 & 507.13 \\
\hline
\end{tabular}

\subsection{Inter-Annual Variability of the Water Balance}

In which mean is the average value of the water balance component from 1990 to $2007, \mathrm{~S}$ is the standard deviation of the value of the component in the study year, $\mathrm{C}_{\mathrm{V}}$ is the coefficient of variation, and $\mathrm{R}$ is the range of the values [11].

We selected $\mathrm{C}_{\mathrm{V}}$ as a statistical parameter to analyze the annual water balance variability because it is not sensitive to the size of the values. It only expresses the extent of dispersion of the values about the mean.

From Table 5 PET shows a lower $\mathrm{C}_{\mathrm{V}}$ value, which implies the potential evapotranspiration of the watershed vary only slightly from year to year. As a result PET with $\mathrm{CV}=0.021$ can be expressed with its mean value, and it can be used as a catchment signature.

$\mathrm{W}$ (soil wetting) with $\mathrm{C}_{\mathrm{V}}=0.118$, and $\mathrm{P}$ (precipitation) with $\mathrm{C}_{\mathrm{V}}=0.105$, can also be used as a catchment characteristics, since they are relatively stable. U (base flow),


respectively, shows a higher dispersion about the mean. It implies stream flow and base flow are exposed to higher fluctuation year to year; as a result they should not be used as catchment characteristics. This conclusion can also be drawn from figure 3 .

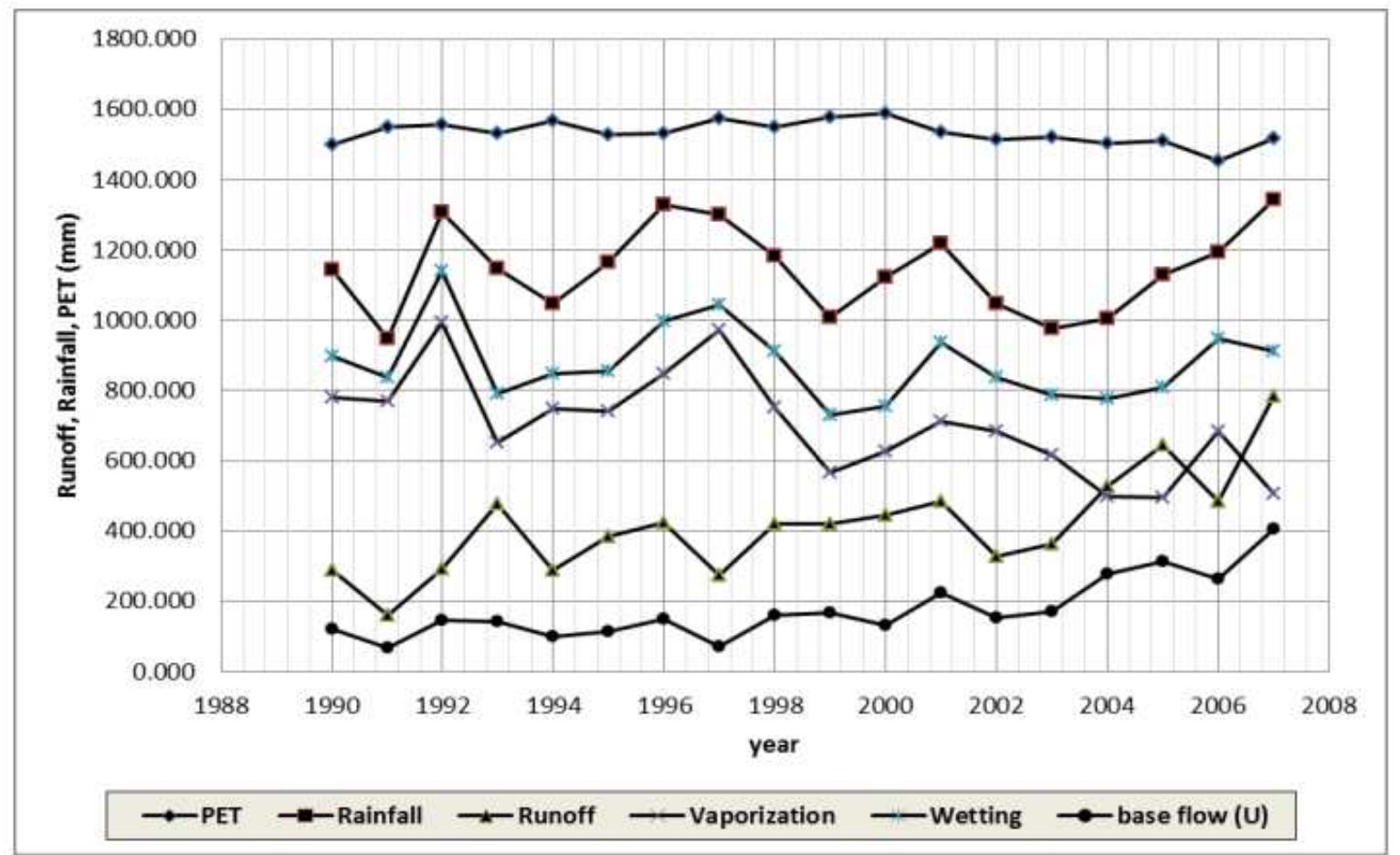

Figure 3. The relationship between water balance components. 
Table 5. Inter-annual variability of water balance component.

\begin{tabular}{llllllll}
\hline Statistics & P & Q & S & U & W & V & PET \\
\hline Mean & 1144.60 & 416.31 & 240.17 & 176.13 & 878.52 & 702.39 & 1533.56 \\
S & 119.71 & 141.38 & 71.87 & 85.96 & 103.61 & 140.32 & 31.79 \\
Cv & 0.11 & 0.34 & 0.30 & 0.49 & 0.12 & 0.20 & 0.02 \\
R & 395.31 & 625.26 & 287.15 & 338.10 & 407.71 & 497.71 & 133.22 \\
\hline
\end{tabular}

\subsection{Climate and Landscape Relationship}

Relevant components of the water balance are plotted in figure 3 to make a relationship and comparison between climatic characteristic and the landscape.

Out of the total water balance components, Vaporization (V), and soil wetting (W) are primarily determined by landscape characteristics of the watershed. While precipitation $(\mathrm{P})$, and potential evapotranspiration (PET), are more the manifestation of the climate. To determine the relationship between the climatic predictors and the landscape predictors, it is essential to determine the relationship between climate and landscape variables.

The relationship between more interdependent components is plotted in graph below. In all study years potential evapotranspiration is much greater than vaporization (Figure 4 ), this implies the amount of actual water vaporized is below the capability of the watershed to vaporize. The average humidity index is 0.747 with a standard deviation of 0.08 . According to UNEP classification, the watershed is humid (i.e. $\mathrm{HuI}>0.65$ ), from this deduction we can conclude that the watersheds is water-limited.



Figure 4. Relationship between HI and HuI.

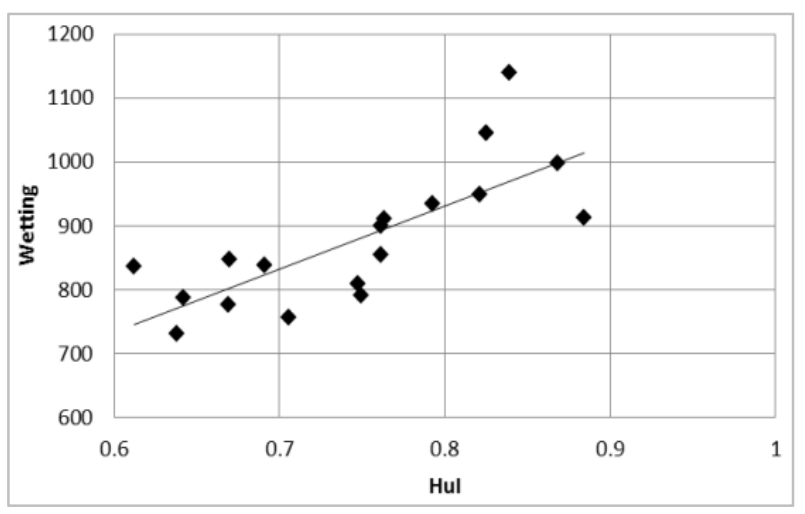

Figure 5. Soil Wetting vs. Humidity index relationship.
From the graph, base flow is generally medium and propagates in the same way as stream flow, because the soil interception is good. This conclusion can also be drawn from the relationship between precipitation and wetting. As it is seen from the graph Precipitation, and Wetting are approximately equal (Figure 5). However, a larger fraction of precipitation runs off and precipitation extremely exceeds wetting.

\subsection{Power of Climate Variables on Hydrologic Partitioning}

As was described above the most dominant climate variables in the hydrologic partitioning are precipitation, and potential evapotranspiration. Therefore the power of climate variables on hydrologic partitioning can be implicitly represented by the power of Humidity Index (the ratio of precipitation to potential evapotranspiration).

Scatterplots and correlation analyses for the climate variables $P$ and PET (which are manifested by HuI), compared with $V$ and $W$, (which are manifested by the Horton index, $H$ ), suggest power law relationships between climate varieties and the Horton index varieties (Figure 6).



Figure 6. Precipitation-soil wetting relationship.

$\mathrm{HI}$ is the measure of ecosystem to consume the available water efficiently. When the available water is small it is clear that the ecosystem will use the deficient water effectively, in case when the available water exceeds a certain limit there may be some sort of water as a surplus; Figure 1 shows this relation.

From Figure 4 the slope of Humidity Index versus Horton index is negative. Negative slope implies decreasing function. As Horton index increase, humidity index gets decreased, this means the effective consumptive use of the watershed increase when the available water is low.

The relationship between soil wetting and humidity index 
is strong, due to the fact that humidity index is directly related to available water, and soil wetting is the part of available water intercepted by the ecosystem.

It is not surprising that soil wetting will increase with the increment of available water. The correlation strength is the measure of the efficiency of the soil to intercept available water in the climate.

Not surprisingly soil wetting is dependent on available precipitation. As it can be depicted from (Figure 3) precipitation and soil wetting are very close, implying that more part of the precipitation is partitioned to soil wetting and lesser part of it as a runoff. A good relation was also established between precipitation and soil wetting. One can conclude from this that, the watershed has a good infiltration capacity.

The potential evapotranspiration, which is the manifestation of available energy with in the watershed, is much greater than the actual evapotranspiration (Figure 3 ). We can assume this is either due to high infiltration capacity of the soil horizon or due to high available energy while the water is limited.

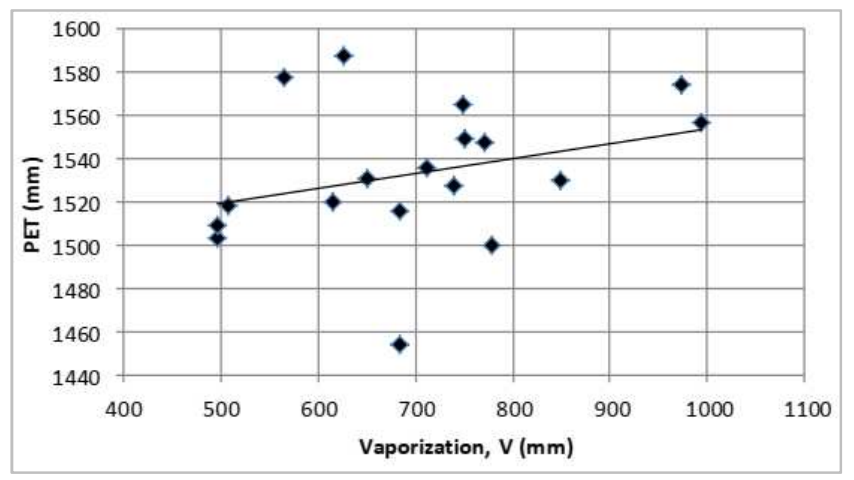

Figure 7. PET-vaporization relationship.

\section{Conclusions and Recommendations}

\subsection{Conclusion}

A hydrologic partitioning behavior of a small, humid watershed with an average $\mathrm{HuI}$ of 0.747 and a standard deviation $\mathrm{S}=0.08$, was studied in Oromia Regional State, Borena Zone, to determine the annual water balance components, with hydrologic indices. The inter-annual variability of water balance components and interrelationship between climate and landscape variables was also investigated. The result revealed that PET with $\mathrm{C}_{\mathrm{V}}=0.021, \mathrm{P}$ with $\mathrm{C}_{\mathrm{V}}=$ 0.105 , and $\mathrm{W}$ with $\mathrm{C}_{\mathrm{V}}=0.118$ from the water balance components; and $\mathrm{HuI}$ with $\mathrm{C}_{\mathrm{V}}=0.107$, and $\mathrm{HI}$ with $\mathrm{C}_{\mathrm{V}}=0.127$ out of the hydrologic indices are relatively stable year to year. Therefore these variables can be used as watershed characteristics to express the watershed by their mean value.

\subsection{Recommendation}

There is much that could be done to improve and enhance a study like this one. To insure the accuracy and reliability of the output there should be much effort to improve the quality and availability of different input data. We had enforced to use Hargreaves et al (1985) equation, to estimate the potential evapotranspiration, while Penman Montieth method would give a good result, due to unavailability of input data. MWRE and ENMA should increase the type of data to be collected, and the area of coverage to alleviate this problem. We have used Hargreaves et al empirical formula which was primarily developed for US watersheds to compute PET, while empirical formulae are both space and climate specific.

There should be much effort to develop such empirical formulae applicable to Ethiopian watersheds.

Our analysis is annual base which neglect minor water loses, due to the assumption that those minor losses will implicitly include to annual water balance components in annual time scale. The same study with intra-annual time scale like; monthly, ten daily, and so on should be developed to account for those minor losses.

\section{References}

[1] B. Rao, Sandeep, V. M., V. U. M. and B. Venkateswarlu, 2012. Potential Evapotranspiration estimation for Indian conditions; improving accuracy through calibration coefficients, All India Co-ordinated Research Project on Agro meteorology, Central Research Institute for Dryland Agriculture, Hyderabad. 60p.

[2] C. Yeung, 2005. Rainfall-runoff and water-balance models for management of the Fena Valley Reservoir, Guam: U.S. Geological Survey Scientific Investigations Report 20045287, $52 \mathrm{p}$.

[3] D. Brooks, A. Troch, M. Durcik, E. Gallo and M. Schlegel, 2011. Quantifying regional scale ecosystem response to changes in precipitation, resources research, vol. 47 , w00j08, doi: 10.1029/2010WR009762.

[4] E. R. Dahmen, M. J. Hall. (1990). Screening of hydrological data, International Institute for.

[5] Eckhardt, K. (2005). How to Construct Recursive Digital Filters for Base flow Separation,. 507-515.

[6] J. Charlier, R. Moussa, P. Cattan, Y. Cabidoche, and M. Voltz, 2009. Modeling Runoff at the plot scale taking into account rainfall partitioning by vegetation: application to stem flow of banana (Musa spp.) plant, Journal of Hydrology and Earth System Sciences. Accessed on April, 26, 2014, www.hydrolearth-syst-sci-discuss.net.

[7] L. Erie, O. French, D. Bucks, and k. Harris, 1982. Consumptive use of water for major Crops in the southwestern United States, United State Department of Agriculture.

[8] M. Pidwirny, (2006). Actual and Potential Evapotranspiration, Fundamentals of Physical Geography, 2nd Edition, accessed on 13, Jun, 2014, http://www.physicalgeography.net/fundamentals/8j.html).

[9] M. Sivapalan, A. Mary, J. Ciaran, X. Xu and A. Troch, 2011. Functional model of water balance variability at the catchment scale: 1; Evidence of hydrologic similarity and space-time symmetry, Water resources research, VOL. 47, W02522, doi: 10.1029/2010WR009568. 
[10] S. Maples, Introduction to GIS Mapping, and ESRI's Arc GIS Software, accessedon, May 26, 2014. www.library.yale.edu/maps.

[11] S. Tekleab, S. Uhlenbrook, Y. Mohamed, H. Savenije, M. Temesgen and J. Wenninger, 13 July 2011 Water balance modeling of Upper Blue Nile catchments using a top-down approach, Hydrol. Earth Syst. Sci., 15, 2179-2193.

[12] T. Taffese, 2012. Physically based rainfall- runoff Modeling in the northern Ethiopian highlands: the case of Mizewa watershed, Water resource engineering, Institute of Technology, Bahir Dar University.
[13] T. Wagener, C. Kelleher, F. Pianosi and B. McGlynn, 2014. Understanding hydrologic Partitioning: Combining mechanistic modeling with signature analysis to understand controls on hydrologic behavior in head water catchments, Geophysical Research Abstracts Vol. 16, EGU2014-10508.

[14] UNEP, 1997. Structural and institutional guidelines for land resources management in the 21st century, Jun, 18, 2014. http://www.fao.org/fileadmin/templates/nr/images/resources.

[15] V. Ponce. (1995). A conceptual model of catchment water balance: Formulation. Journal of Hydrology, 27-40. 